\title{
Assessing dictionary skills
}

\author{
Mari Carmen Campoy-Cubillo ${ }^{1}$
}

Received: 11 May 2015/Accepted: 8 July 2015/Published online: 1 August 2015

(C) Springer Berlin Heidelberg 2015

\begin{abstract}
This article discusses the role of dictionary skills in language learning as part of professional reference skills and as life-long language learning skills. It advocates for the integration of these skills in the language teaching and assessment cycle in a systematic way. Drawing on Nesi's (Dictionaries in language learning. Recommendations, national reports, and thematic reports from the TNP sub-project 9: dictionaries, 1999) and Lew's (Electronic lexicography in the 21st century: thinking outside the paper, 2013a) stages of dictionary use skills, it suggests that assessing dictionary skills is necessary if we want to study and analyze these skills in dictionary users under a common framework. Research on the use of dictionary skills in different countries and under several situations as well as responding to different reference needs can only be systematized if dictionary skill assessment is carried out under the same general assessment criteria. Several dimensions for assessing dictionary skills are considered.
\end{abstract}

Keywords Dictionary skills · Skills assessment - Language learning · CEFRL · CEFRL_J

\section{Introduction}

Hartmann and James (1998, p. 117) define reference skills as "the abilities required on the part of the dictionary user to find the information being sought." These abilities have been studied by different authors in the past decades. Hartmann (1987) provides a detailed description of research carried out on this issue up to 1987. Research on dictionary skills in the following decades has focused on a number of different areas. Dictionary skills are primarily studied in relation to the

Mari Carmen Campoy-Cubillo

campoy@uji.es

1 Universitat Jaume I, Castellón de la Plana, Spain 
work of Foreign Language students while developing tasks in receptive skills (Scholfield 1982, 1999; Tono 2001), productive skills (Bishop 2000, Rundell 1999), receptive and productive skills (Tono 2000), translating (Atkins and Varantola 1998; Sánchez Ramos 2007), assessment (Tono 1988; East 2008), or reference and information needs (White et al. 2008). The relationship between L1 dictionary skills and other language skills together with how dictionary use aids progress in selfteaching of different language skills is also examined, for instance, in Beech (2004). The need for training in dictionary skills (regarding both teachers and learners) and the development and description of strategies on dictionary use is highlighted in the work of Chi (1998), Bishop (2000), Carduner (2003), Lew and Galas (2008), or Ranalli (2013) to mention just a few. Research has also been conducted regarding dictionary skills and how dictionary typology and dictionary micro- and macrostructure affect quality of consultation. In the field of pedagogical lexicography, researchers analyze how dictionaries are elaborated with the main aim of helping learners progress with their language learning process (Tarp 2011). Finally, computer-mediated lexicography brings new perspectives into the field of dictionary skills. In this area, the use of web and electronic dictionaries as learning tools or their integration in multimedia learning platforms (Sánchez and Basanta 2004; Ranalli 2012) or electronic dictionaries (Tono 2000), the study of online dictionary skills (Lew 2013a, b), the analysis of multimodality in dictionaries (Lew 2010), or analyzing computer-mediated dictionary users as a new user profile (Lew and de Schryver 2014) open up new doors to dictionary users and dictionary skills research.

\section{What kind of constellation is assembled around dictionary skills?}

The dictionary skills of a language learner depend upon dictionary look-up strategies and the language learners' ability to use the best possible strategy in a particular context and for a specific purpose. Contexts of use may range from educational to vocational to professional ones. Likewise, implementation contexts may vary from classroom task to test to professional implementation contexts. Dictionary skills may be influenced by dictionary skill teaching/learning practice or the lack of it. Moreover, the role of dictionaries in the educational system may determine the development of dictionary skills. Thus, the inclusion of dictionary use and skills in educational programs and syllabi facilitates the development of these skills and enhances the importance of dictionaries as an educational and life-long learning tool (Walz 1990; Wingate 2004).

It is interesting to note how looking up the term dictionary in the Cambridge, Collins, Longman, Macmillan, Merriam-Webster, and Oxford online dictionaries provides definitions that refer to the information contained in dictionaries, the format dictionaries may take, the way information is arranged, and the languages it contains. Definitions for the word dictionary and reference book also refer to the fact that you look them up to find or discover information as they are a reference resource. No mention is made, however, of the important role they play in language learning. Dictionaries are language learning tools. They can be used in classrooms and also as a self-learning resource. But it seems that this role is still not perceived 
as a relevant one. Moreover, no clear picture of the role of dictionaries in language learning is given in syllabi. Whereas grammar and vocabulary are clearly structured in General English and English for Special Purposes courses and tests, no such structure appears to be existent regarding dictionaries. An exception would be translation courses and tests where terminological resources and dictionaries are given full consideration for obvious reasons. Unawareness of the importance of a dictionary when learning a new language is also reflected in the fact that dictionary skills are not included as an important measurement in language testing like other language skills (e.g., reading, writing, speaking, and listening). But mastering dictionary skills is important in the language learning process, particularly regarding reading and writing. Reference skills and dictionary skills, as part of the former, are also relevant to solve problems of communication in the business or working contexts: a proficient dictionary user may solve doubts on deciding the correct word or ways to say something in a particular situation. For instance, he or she may also check whether a message has been properly understood or not or may carry out a more effective reading of information relevant to his/her job aided by dictionaries.

Thus, the purposes, goals, and values of dictionary skills and the context where these skills may be developed (primary/secondary school, undergraduate/graduate/master programs, employment, and professional environments) need to be analyzed, so that the skills can be clearly related to proficiency levels and the abilities defined within such levels.

Language learner dictionary skills are directly related to language proficiency level. But they are also related to the general reference skills of the learner, the purpose of the task, the level of complexity of that task, and the required output. The input mode will also determine the need for dictionary look-up or the lack of it. Thus, reading multimodal texts (for example image plus text) or a clear/defined context in which a word appears may influence the decision or the need to look up information in a dictionary (Fig. 1).

Complexity of task and language proficiency level can be explained in the following example. Beginner students will first need to know the word related to the concept or idea they need to communicate and will later add on information on how to use that word in a more proficient way. Paving this way gradually brings learners from one level to the next one. A beginner student trying to ask for a cup of tea will first need the word "tea" and may later add on verbs like "drink, have," continue with more advanced vocabulary, and try to learn about "taste, sip, pour, enjoy or serve a cup of tea." He or she may combine "tea" with nouns like "towel, bag, pot or ceremony" as well as modify it with words like "herbal, green, iced, or complimentary" and will then use it in expressions like "Would you like some tea?" or "Could I have some more tea?" Thus, the fact that the learner does not know the basic word(s) he/she needs to convey a message is more pressing than being able to use that word in a grammatically correct way, in a way that does not break pragmatic conventions or rules, or in a socially, culturally, and inter-culturally efficient manner.

With low proficiency levels, using dictionaries to look for a translation is also a matter of confidence. Even if a learner has grasped the meaning of a word, checking 


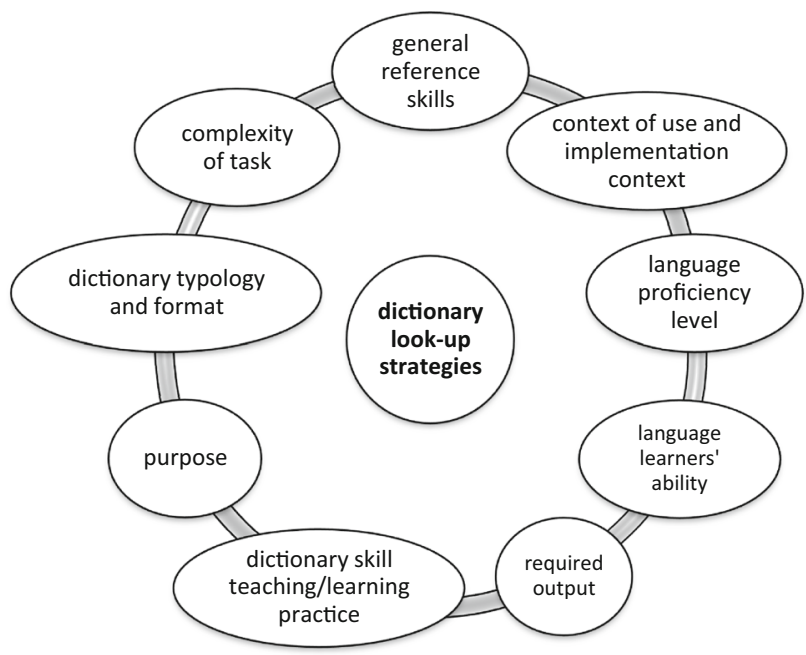

Fig. 1 Dictionary skills constellation

this meaning in a dictionary gets rid of the learner's uncertainty, thus giving them some kind of assurance.

\section{Dictionary culture and dictionary skills assessment}

According to Hartmann and James (1998, p. 41), dictionary culture is "the critical awareness of the value and limitations of dictionaries and other reference works in a particular community" (see also Crowley 1999; Gallardo 1980; Hadebe 2004; Prinsloo 2012). This community value that we have previously mentioned in Sect. 2 above is important in the assessment dimension of dictionary skills. When we talk about "community" we are talking about a cultural context where people in that community have an idea of the value of dictionaries. That value has necessarily been given an educational context too. When educational institutions support the use of dictionaries as learning tools, the value of dictionaries increases. This is so because this support is given a weight in syllabi. But for dictionary skills to have a real value in an educational context, the role of the dictionary in culture needs to be better defined. For instance, research on the value users give to the online dictionaries that they use, the results they get from them and the uses or applications to which they put the results of their searches, or the various purposes they have in using an online dictionary could contribute to an update in dictionary value within a dictionary culture.

As shown in Fig. 2 below, the educational and cultural context of a particular learner or group of learners sets up a cultural view on how dictionary skills are developed with specific goals in mind. In developing criteria, the learner profile needs to be defined not only in terms of background knowledge, first or foreign language experience, or number of languages they know, but also in relation to 


\section{Difetionary euliture}

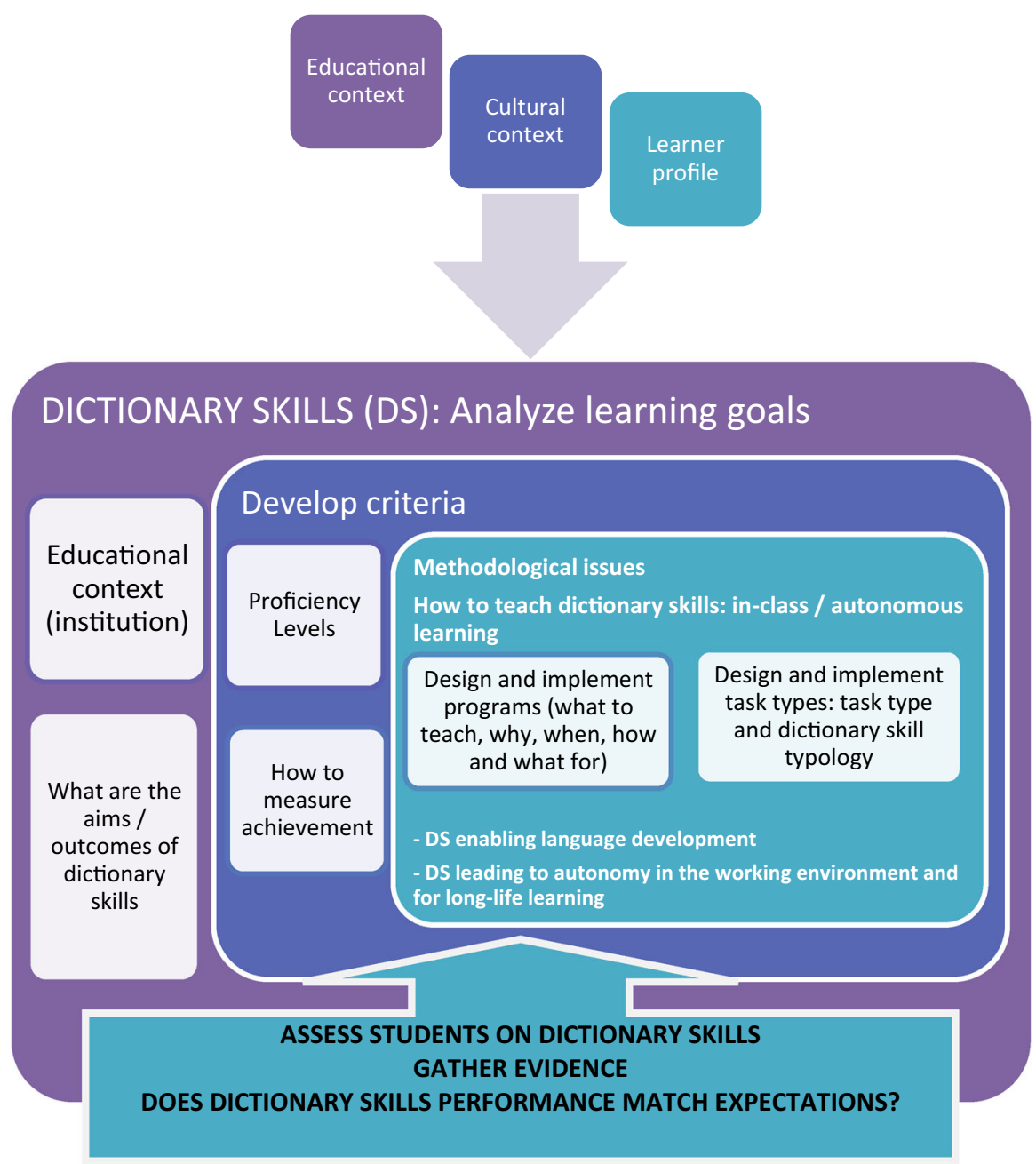

Fig. 2 Assessing dictionary skills

proficiency levels. The design and implementation of a set of dictionary skills tasks that correlate to specific dictionary skills within a range of proficiency levels are necessary in order to have some tools to measure achievement. The requirement of specific outcomes will also determine how these dictionary skills are measured and what for. Since "Language assessment involves obtaining evidence to inform inferences about a person's language-related knowledge, skills or abilities" (Green 2014 , p. 5), dictionary skills assessment needs to complete and repeat the cycle of putting together this evidence through task development and implementation and 
learners' performance. The assessment cycle in language learning is described by Green (ibid., p. 7) as a cycle of activities that go beyond the test event and student performance. This cycle in Green's words also includes:

- deciding on the content of the test;

- scoring the performance;

- deciding on the meaning of the scores obtained; and

- decisions that the scores are used to justify (such as choosing which students to admit to a course or deciding whether to award certificates).

We believe that in the case of identifying and assessing abilities to use specialized dictionaries in professional contexts or proficiency in using lexical databases, recognizing these skills may also form part of the set of criteria that employers may use for choosing employees.

\section{Dictionary skills and dictionary types}

The Commission of the European Communities (2007) defined e-skills as a group of skills including ICT practitioner skills, ICT user skills, and E-business skills. In the era of e-lexicography, when talking about dictionary typology, we need to differentiate between paper and computer-mediated lexicography and to create a correspondence between types of e-dictionary (De Schryver 2003) and dictionary skills. Dictionary e-skills are a combination of dictionary skills, general reference skills, and e-skills. This combination in computer-mediated lexicography also entails the existence of (1) a new kind of dictionary user profile system (including the role of the user in user-generated content (UGC) (Lew 2014), (2) new training needs, (3) a new and more complex dictionary typology, where limits between one type of dictionary and another may sometimes be blurred, and (4) new search methods or "novel ways of accessing lexicographic data" (Lew 2013a, p. 16). The latter is particularly complex in web dictionaries.

The dictionary user profile in e-lexicography is bound to be determined in the first place by the users' e-skills and by their multimodal skills or ability to combine information presented in different modes such as written, audio, video, pictorial, or graphic [Campoy-Cubillo and Querol-Julián (work in progress)]. Additionally, the active role of the dictionary user in creating new content may give way to a new type of user who is more aware of the dictionary contents and ways to update information in online dictionaries. Yet, as Lew (2014) points out, not all users are properly trained or able to produce relevant and informed lexicographic data: a subset of advanced, trained users may provide more successful, useful contributions, for instance, regarding language equivalents in bilingual and multilingual online projects or dictionaries. Lew (ibid.) also discusses the role of motivation in UGC and highlights three types of motivation the users may have when it comes to deciding to become an active dictionary user. These include psychological, social, and economic motivations. Regarding language learners' motivation for creating new content, we feel that the second (psychological motivation) could have an 
interesting role for language learning. Thus, collaborating in the content creation of an online dictionary may give learners the sense of being a good learner, a proficient student, and in this way provide positive motivation to continue learning that language.

New training for teachers and students is needed for dictionary skills as not all teachers or learners are good at using internet or other computer-based resources. Furthermore, it takes time to become acquainted with new products and with a huge variety of online lexical resources. It also takes time for teachers to develop the ability to discern which material is useful for the classroom.

Campoy-Cubillo (2002) examines cross referencing in online dictionaries and distinguishes different ways to navigate from one part of the dictionary to another. Cross referencing from one word or phrase included in an entry to the entry for that word or phrase is similar to paper cross referencing-only more user friendly and less time consuming. What is new about online dictionaries as information sources is the possibility of linking the dictionary to external and/or other types of information. In this sense, links may be both internal (as part of the dictionary macrostructure and designed as content to be included in it) and external (links to other sites). Links to other sites transform dictionaries into a more powerful learning resource if these linking options have been designed with educationally sensible criteria and when a conscious and informed decision to include one link or another has previously been made. The most frequent options for external links that may enhance the value of online dictionaries are the links to other pedagogical materials (grammars, vocabulary tasks, specific information on usage, worksheets, etc.).

Another way to enhance language learning is to generate dictionaries that are tailored to help with a particular skill in a specific context. A good example is found in Granger and Paquot (2010), who presented a web-based EAP dictionary containing non-technical and function words in academic discourse that has a writing aid for non-natives aiming to write academic texts. In this sense, theirs is a productive dictionary addressing a very specific area of writing. This probably means that the success of the dictionary in helping with the academic writing of their users is easier to ascertain since it addresses a limited - though not smallnumber of text types.

Finally, e-lexicography has made it possible to create customized dictionaries where users decide on the amount of information they get or how they access it. Online resources allow access to multiple dictionaries and in this way may also help users decide which dictionary to use from a range of dictionaries included on the same site. Examples include Cambridge Dictionaries Online, where several Cambridge dictionaries are offered on the same site, and OneLook Dictionary Search, where looking up a word or phrase provides a results page where the user may choose from a large number of online dictionaries classified in different categories (general, business, medicine, slang, technology, etc.). In a way, this could be considered customization of the choice of dictionary type, since the user has a number of dictionaries available and may easily change from one to another, something that was more time consuming and less user friendly in paper dictionaries. Sites like these are good places to introduce dictionary typology to language learners. 


\section{Dictionary skills: stages in the process of dictionary use}

Teaching dictionary skills implies having a clear understanding of the different stages a user goes through when consulting a dictionary. It is a fact that not all dictionaries follow the same format or allow the same search options. Since not all teachers are aware of dictionary look-up processes and that the majority of students have never or seldom been trained in dictionary skills, it is necessary to define the stages and skills involved in dictionary use.

In 1999, Nesi defined six stages in the process of dictionary use:

1. Before study,

2. Before dictionary consultation,

3. Locating entry information,

4. Interpreting entry information,

5. Recording entry information, and

6. Understanding lexicographical issues.

Let us consider these stages taking into account not only what the user does, but what the stages imply in the teaching cycle. In the first stage, Nesi includes (1) Knowing what types of dictionary exist, choosing which dictionary/ies to consult and/or buy, and (2) Knowing what kinds of information are found in dictionaries and other types of reference works.

This first stage, Before Study, is important as part of the assessment cycle in language learning: this knowledge is essential for teachers and educational institutions in order to be able to determine what to assess, how to design dictionary tasks with a specific purpose and outcome in mind and in which situations these tasks and their evaluation will take place.

Familiarity with dictionary typology and the specific information each dictionary type contains implies having dictionaries available in the classroom, be it in paper or electronic format. Since the majority of students in Spain tend to use online dictionaries, this also entails a need for further research on web dictionary typology. It is not easy to determine what is and what is not a dictionary in an internet environment. If we are thinking about what kinds of dictionaries should be used to promote, teach, and test dictionary skills, research should also consider what a pedagogical dictionary is and which dictionaries are relevant for/in the language learning and professional situations.

In the language learning cycle, these two stages may be affected by or related to teacher training, teacher instruction, and/or self-instruction. It may also be related to dictionary guidelines, their use, and the way in which the guidelines can be developed in computer-mediated lexicography.

Instruction on dictionary use may involve a more complex design in cases where dictionaries include corpora as part of their macrostructure or in the form of additional examples. This would be the case of dictionaries designed with a particular user profile: professional/learner translators or advanced learners. Things will be further complicated when more than one language is included. Search 
techniques (Pastor and Alcina 2010) in complex electronic dictionaries and how to develop these techniques effectively should be part of translator and advanced learner strategy training. They should also be part of dictionary user training, but should of course be adapted to all language proficiency levels and different learner/ user needs.

Stage two in Nesi's (1999) category is called Before Dictionary Consultation. This is the stage in which users decide whether dictionary consultation is necessary. Lew (2013a) points out that the issue here is weighing up the cost of the consultation against the benefits of the consultation. He says that, if integrated with other language skills, digital dictionaries are more beneficial than paper ones.

Stage two also includes what to look up. In language testing, these two issues are difficult to assess unless eye-tracking protocols (Tono 2011) or log files are used as part of the research or information gathering methodology. In addition, this stage also includes the query or expression introduced in the dictionary in the case of e-dictionaries. It presupposes the knowledge of dictionary types as it includes deciding which dictionary could satisfy the purpose of the consultation. In dictionary search engines like Lexicool, this process may be complicated and require practice to optimize the dictionary type search. And finally, it incorporates the ability to identify the word class and to guess the meaning of the look-up item from the context.

Stage three in Nesi's classification is Locating Entry Information. The main skill at this stage is to understand the structure of the dictionary. This means, on the one hand, knowing which parts of the dictionary are relevant for the look-up and, on the other, understanding the writing system and principles under which a language is organized. Since the writing system of a language (logographic, consonant, or alphabetic) influences the organization principle of the dictionary, even the ability to deal with the system varies with the students' proficiency levels. It is also affected by whether the students' first and second languages use the same writing systems. This takes us to an important issue in language assessment: levels of difficulty in learning a foreign language may be affected by the contexts where they are learnt, the similarity of the first language (L1) and the second language (L2), differences in cultural and pragmatic issues between the languages, or purpose and motivation to learn the language, among others.

When talking about levels of language proficiency, we may elaborate a common framework to work with. But the specific situation where the framework is used will necessarily verify, redefine, or adapt those levels. Thus, the Common European Framework of Reference for Languages (CEFRL) was created to provide a basis for the elaboration of syllabi and the assessment of language proficiency and is organized into six different proficiency levels that are related to language skills and cater for the basic, independent, and proficient users or learners of the language. The CEFRL_J, a modification of the CEFRL for English language education in Japan (Negishi 2012; Tono and Negishi 2012; Runnels 2014), responds to a specific need to redefine the European framework and adapt it to the Japanese educational context and needs. After studying and analyzing how these levels mismatched those of Japanese students, a need was perceived to branch the European Framework levels in Japan, and this need has led to the development of the CEFRL_J, which includes 
the subdivision of the A and B levels into nine new levels, adds a new pre-A1 level, and aims at adapting the can-do descriptors (describing what students can do at each English language proficiency level in different domains) to the Japanese context.

Just as the language proficiency levels are described to reflect learners' skills in reading, writing, speaking, and listening, as well as to analyze a range of communicative contexts, themes, tasks, and purposes and language competence levels, a scale to measure dictionary skills needs to be designed as well.

Such a scale for dictionary skills should concern all the other aspects included in Nesi's (1999) third and fourth stages. These skills describe the abilities needed to understand, interpret, and process look-up results (as defined by Pastor and Alcina 2010). The remaining skills in the Locating Information in stage three include: understanding grapho-phonemic correspondence (and the lack of it), understanding the use of wildcards (Lew 2013a) in electronic dictionary searches, choosing among homonyms, finding derived forms, finding multi-word units, understanding the cross-referencing system in print dictionaries, and hyperlinking in electronic dictionaries (Nesi 1999).

Stage four, Interpreting Entry Information, is the stage that most faithfully reflects the dictionary users' abilities, since it is concerned with the ability to interpret the information that has been found, distinguishing relevant from irrelevant information. The first subskill in this stage, distinguishing the component parts of the entry, can be seen as basic or advanced depending on the dictionary. While learners' dictionaries may be organized in a way that allows for easy distinction of the parts of their entries (also aided by typography), the wide range of online dictionaries and the format of their entries can be something very different and complex (see Pastor and Alcina 2010 for their description of the search result).

Other components of the Interpreting stage include: finding information about the spelling of words; understanding typographical conventions and the use of symbols, numbered superscripts, and punctuation; interpreting IPA and pronunciation information; interpreting etymological information; interpreting morphological and syntactic information; interpreting the definition or translation; interpreting information about collocations; interpreting information about idiomatic and figurative use; deriving information from examples; and interpreting restrictive labels. E-dictionaries include in this category the ability to find and use audio and video files for acoustic and visual types of information (Lew 2013a).

Other aspects of the fourth stage are the skills of being able to use and refer to additional information (front matter, appendices, and hypertext links). The nature of this additional information can change significantly from one source to another and may contain complex sources of information for specialized online dictionaries, as seen in Campoy-Cubillo (2002) and in Pastor and Alcina (2010).

We believe that the last skill in this stage, verifying and applying looked-up information, should be given a separate status as this implies higher skills of information and knowledge transfer.

Stage five, Recording Entry Information, is also important since the dictionary user will need to find a way to record information that will be useful for the task at hand but also for future reference. In a working environment, for instance, being able to record and systematically organize the information obtained may save 
consultation time in the future and may also help in developing the kind of language or linguistic expressions that are most frequently needed in that working environment.

Nesi (1999) distinguishes a sixth level, Understanding Lexicographical Issues, which is relevant not only for lexicographers but for all the professionals involved in the language teaching cycles. Thus, knowing about dictionary culture, knowing lexicographic terminology, knowing what people use dictionaries for, understanding the principles and processes of dictionary compilation, and being able to critique and evaluate dictionaries, as well as being able to compare dictionary entries or to recognize defining and translating styles, are skills that need to be mastered by materials and test designers as well.

\section{Self-assessment of dictionary skills}

Hartmann (2000, p. 389) discusses ways to deal with dictionary skills research and raises three questions that are related to self-assessment:

1. Self-assessment of reference skills ('How well do you think you will do without dictionary consultation?'),

2. Look-up skills while referring to a particular dictionary ('Where did you look up $\mathrm{X}$, and what did you find?'), and

3. A chance to reflect on the exercise ('How well do you think you did?').

When asked to evaluate their dictionary skills, dictionary users' self-assessment is usually directed toward simple searches they typically carry out, such as identifying the definition of a word. Most users, particularly those who are not studying or working in a language area, do not consider complex searches as part of their skills and may even be totally unaware that such searches exist. Therefore, they cannot evaluate their skills beyond their current use of dictionaries. The issue here is this: if they just use the dictionary for looking up translational equivalents or definitions, and are able to find what they want, they are content with their search results, but they cannot judge how good they are with other dictionary skills because they are confined to a limited set of skills. It is for these reasons that self-assessment of dictionary skills cannot be carried out properly unless users are instructed on all the stages described above, or unless they are reminded in a post-test or post-questionnaire that includes some kind of description of the full range of dictionary skills. Self-assessment skills are also important as a guideline for autonomous learning self-assessment.

\section{A framework for dictionary skills proficiency levels}

Dictionaries and reference materials are mentioned in a few sections of the CEFRL, but their role in the language learning process is not analyzed in detail. Let us examine all the references to dictionaries and reference works in the Council of Europe (2001) document. 
Dictionaries are mentioned from three different angles within the framework. One is the "dictionary as a text type." When speaking about the context of language use, the CEFRL explains how the acts of language use occur in a specific situation within one of the domains or areas around which we organize social life. These domains may include the personal, public, occupational, and educational ones. In this sense, the CEFRL includes dictionaries as a type of text that can be found within the educational domain. If reading skills include the ability to read and interpret all kinds of texts including dictionaries, then instructions on how to read and process information contained in dictionaries should be part of the reading skills descriptors. It should also be pointed out that being able to find and understand dictionary information may aid text reading, but interpreting and applying this information may also lead to text production. Thus, dictionary skills can be clearly related to the skills of reading and writing. In fact, most users tend to use dictionaries in relation to these two language skills: reading and writing (and use dictionaries for listening and speaking purposes only occasionally).

If dictionaries are considered one of the main educational text types and also an important tool within the practice of reading and writing skills, this means that educational institutions should consider dictionary availability (electronic, web, or paper) and dictionary skills instruction within educational programs and that teachers need to be trained to teach dictionary skills.

The second allusion to dictionaries is "in relation to reading and writing skills." In this sense, dictionaries are part of the reading or writing skills descriptors in the sense that their users may need a dictionary to carry out a specific (reading/writing) task. The CEFRL provides several statements regarding the learners' reading ability in situations in which the use of a dictionary is seen as an important part of the reading process, or at least as an action that tells us about how learners may or may not manage their language knowledge when reading. Thus, when discussing reading activities, illustrative scales are presented for overall reading comprehension, reading correspondence, reading for orientation, reading for information and argument, and reading instructions (Council of Europe 2001, pp. 68-71). When the different reading activities are framed within a proficiency scale, the use of dictionaries appears to be related to a few of these activities, for instance in the Reading for information and argument scale:

B2 Can obtain information, ideas, and opinions from highly specialized sources within his/her field.

Can understand specialized articles outside his/her field, provided he/she can use a dictionary occasionally to confirm his/her interpretation of terminology.

Or in the Reading correspondence scale:

C1 Can understand any correspondence given the occasional use of a dictionary.

In these statements, the CEFRL takes into consideration to what extent the learner needs a dictionary or whether they are able to carry out a task on his/her own. Thus, phrases like "provided he/she can use a dictionary" and "given the occasional use of a dictionary" are used in the sense that it is believed that they will have to use a dictionary occasionally to fulfill specific tasks. These statements can 
easily be related to the use of general English dictionaries and also specialized dictionaries. In the professional environment, if these statements are linked to our recommendation to include dictionary skills as part of syllabi and of major language assessment tests, it could mean that for specific tasks a learner can be asked to use a dictionary to see if he/she is able to perform an occupation-related task with the use of a dictionary. This task could be to understand a letter from a client for business students or to answer an email from a client who is asking for details or making a complaint in the tourism sector.

In the DIALANG ${ }^{1}$ self-assessment statements for writing, the need to use dictionaries as a means to process information (or lack of it) is also included at A1 and $\mathrm{C} 1$ levels:

A1 I can write short letters and messages with the help of a dictionary.

C1 I can usually write without consulting a dictionary.

DIALANG also describes ${ }^{2}$ levels $\mathrm{A} 1$ and $\mathrm{B} 2$ in terms of what the learner can understand and the conditions and limitations they may have, i.e., when and if a dictionary is necessary for certain reading and writing tasks at specific proficiency levels:

B2 Understand the essential meaning of correspondence in my field and specialized articles outside my field (with dictionary).

B2 Dictionary required for more specialized or unfamiliar texts.

A1 Apart from the most common words and expressions, the writer needs to consult a dictionary.

Third, dictionaries are mentioned when describing the "general competencies" of an individual, dictionary use and e-skills are shown as part of a learner's ability to learn (p. 12):

Ability to learn: Skills and know-how: e.g., facility in using a dictionary or being able to find one's way easily around a documentation center; knowing how to manipulate audiovisual or computer media (e.g., the Internet) as learning resources. (Council of Europe 2001, p. 12)

Similarly, the Association of Language Testers in Europe $\left(\mathrm{ALTE}^{3}\right)$ provides a list of study statements for which they provide indications regarding language learning concerns or points of interest, the activities that may be related to those concerns, the environments in which they may happen, and the language skills required. Here (Council of Europe 2001, p. 257), reference skills are one of the concerns and are defined as the activity of "accessing information (from a computer base, library, resource, dictionary, etc.) for reading and writing."

\footnotetext{
${ }^{1}$ DIALANG is a CEF assessment system and an application for diagnostic purposes and self-assessment. See Council of Europe (2001, Appendix C: The DIALANG scales, pp. 226-243). See also Information about DIALANG: http://www.lancaster.ac.uk/researchenterprise/dialang/about.htm.

2 Council of Europe (2001, Appendix C, pp. 239-240).

3 ALTE http://www.alte.org.
} 
To sum up, dictionaries are a specific kind of text, a tool that helps students develop their writing and reading skills and part of the learner's ability to learn and be able to access (linguistic) information.

It is important not to lose sight of the fact that dictionaries are tools for which users need to develop specific skills if they want to achieve satisfactory results. Thus, although they may form part of other language skills such as reading or writing, dictionary skills need to be defined in isolation to better understand those skills and how part of the skills can be integrated in the description of other language skills.

Taking into account all the points and remarks considered in the CEFRL on dictionaries and using Nesi (1999) and Lew (2013a) as a source for relating dictionary skills to the CEFRL proficiency framework, we will provide a proposal for defining dictionary skills according to proficiency levels. Table 1 is a possible working classification of descriptors and proficiency levels to which dictionary skills might correspond.

This table is based on seven criteria related to dictionary skills: decide, locate, understand, interpret, evaluate, record, and implement. The deciding and locating descriptors will refer to the first stages in the dictionary consultation process and should be paid special attention in the dictionary skills training phase, even if they seem very simple at first sight. Making the right decision can save valuable time, and without being able to locate the sought-after information one cannot go on to the following steps. Understanding and interpreting information are more demanding tasks that are prerequisites to being able to apply the information obtained to the purpose with which one set out. For this to happen, one needs to evaluate one's search results in terms of validity, so as to decide whether to terminate the consultation or to carry on with one or more look-up actions for the desired information. Registering the information will aid being capable of implementing it and will also enrich our language learning management and progress.

Table 1 is an attempt to relate dictionary skills to proficiency levels. There are many difficulties that need to be taken into account regarding the use of dictionaries and the relation they may have with language skills. One of the main problems is the fact that training in dictionary use is not uniform across countries or even within the same educational institution. As stated elsewhere in this article, the absence of dictionary skills in syllabi may be one of the reasons for this lack of uniformity. Another reason is that it is not usually included in the teacher training programs. What learners can do with dictionaries does not so much depend upon their language level or teacher dictionary skills input (which is usually scarce), but upon personal learning abilities and self-learning skills. In this sense, dictionary skills may also be a good and concrete indicator of self-learning skills.

Another issue that further complicates this dictionary skills framework is that it needs to be related to the different dictionary types and whether they are designed according to language proficiency or not (i.e., whether they are pocket dictionaries, dictionaries for beginners, intermediate, or advanced learners). Using mono-, bi-, or multilingual dictionaries may also relate to proficiency levels in different ways. Thus, reading a definition in a monolingual dictionary is not the same as reading and understanding one in a bilingual dictionary. 


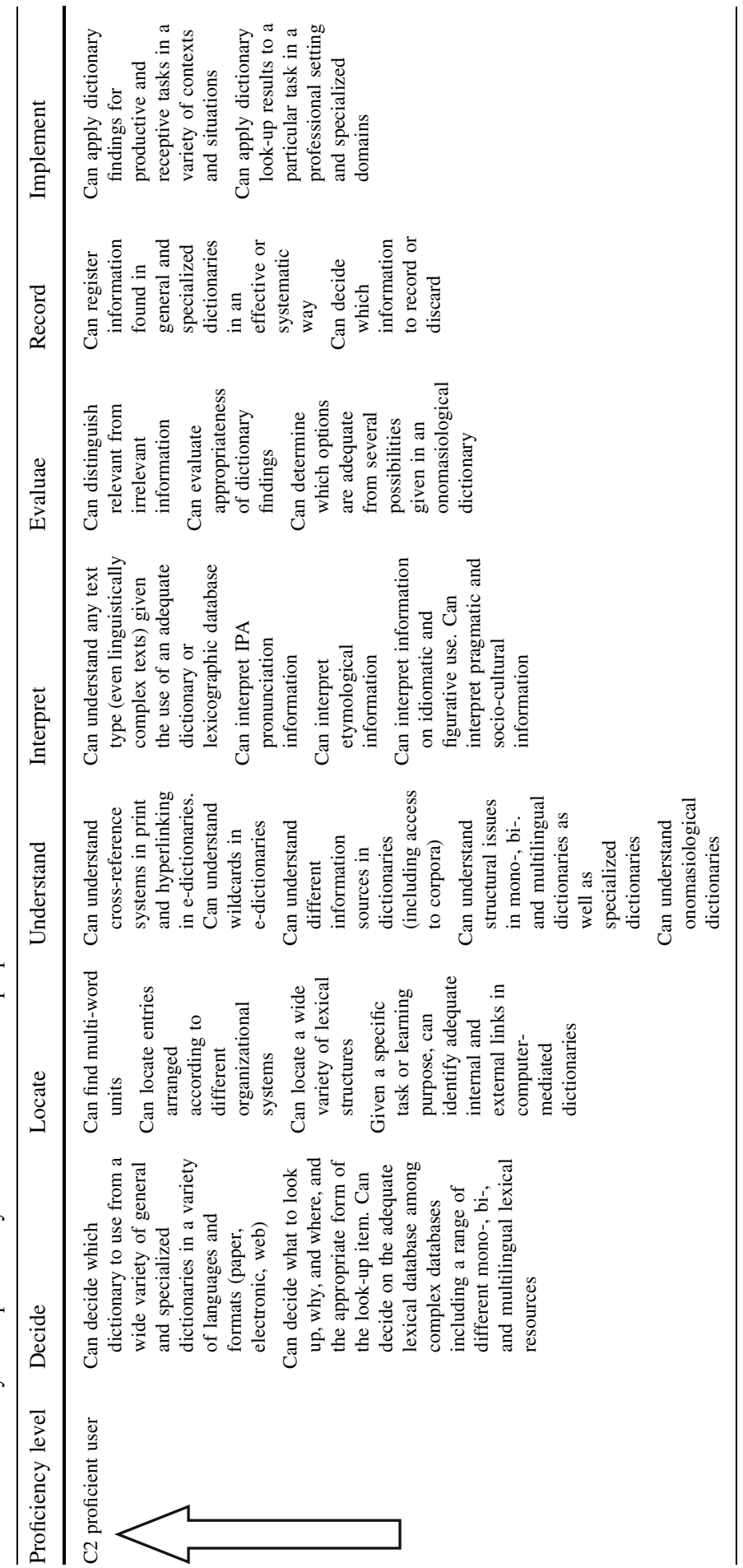




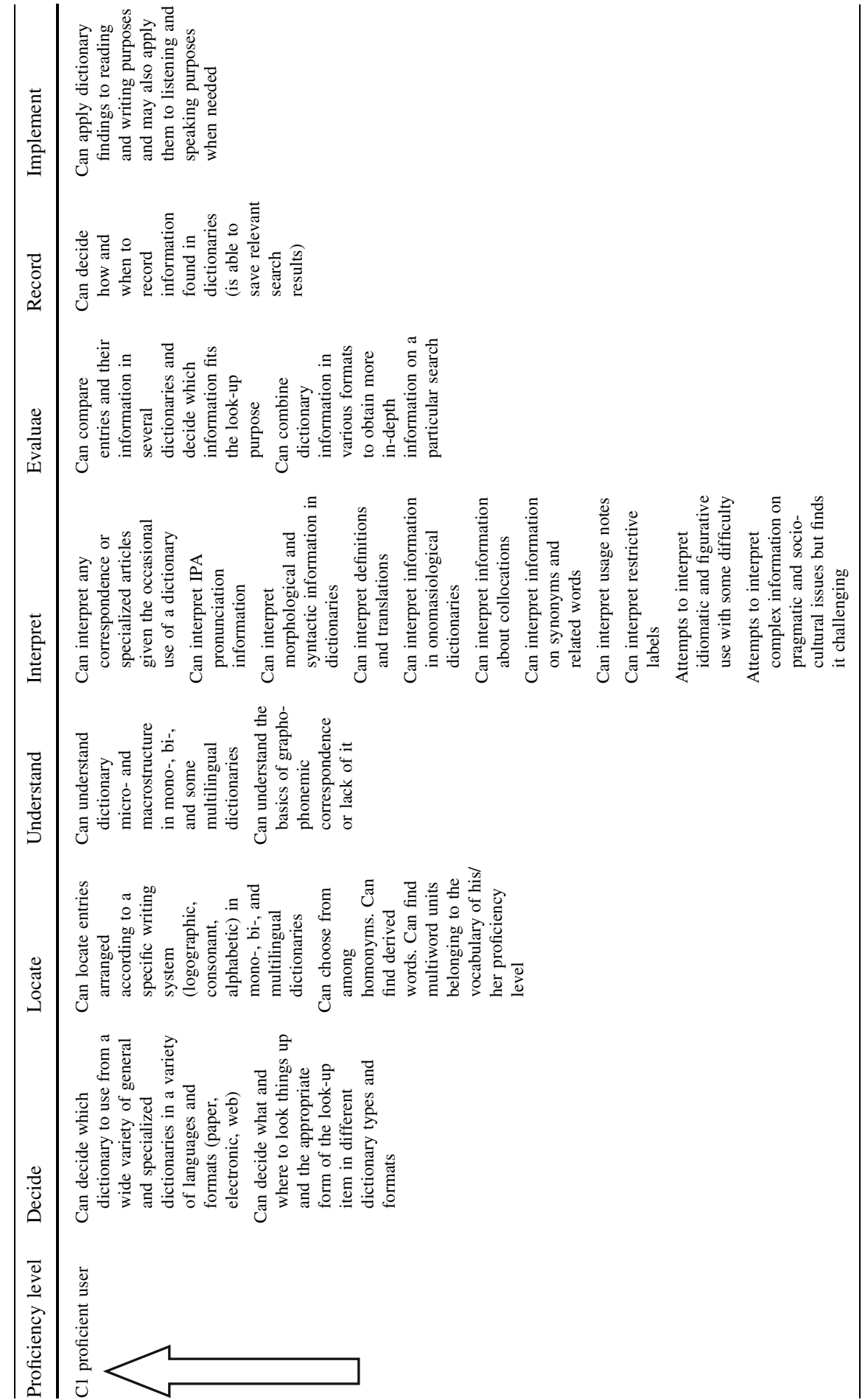




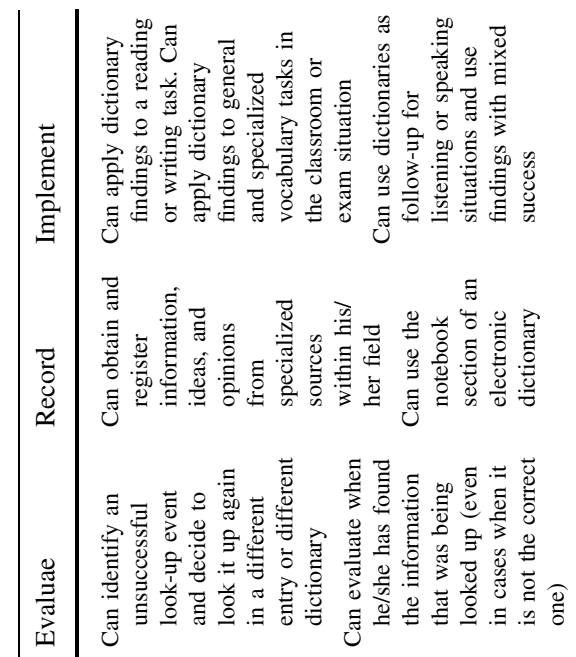

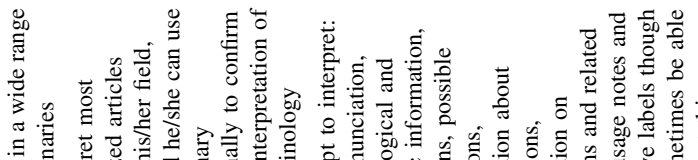

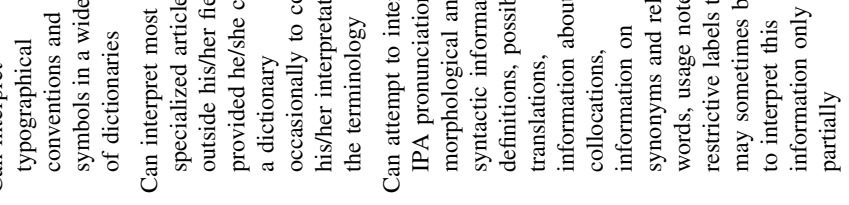

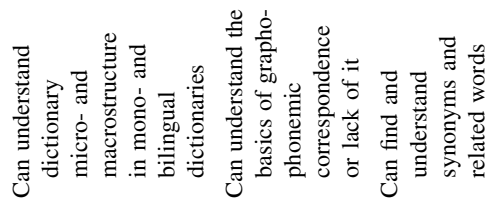

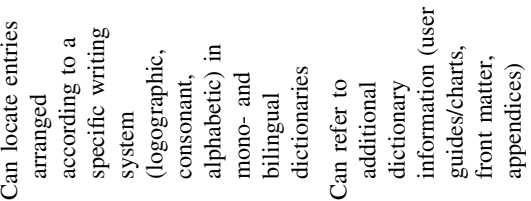

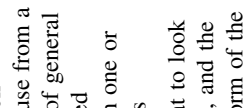

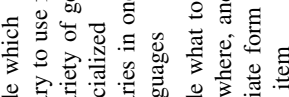

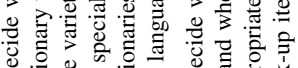

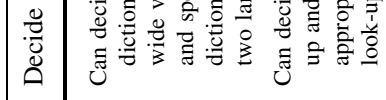




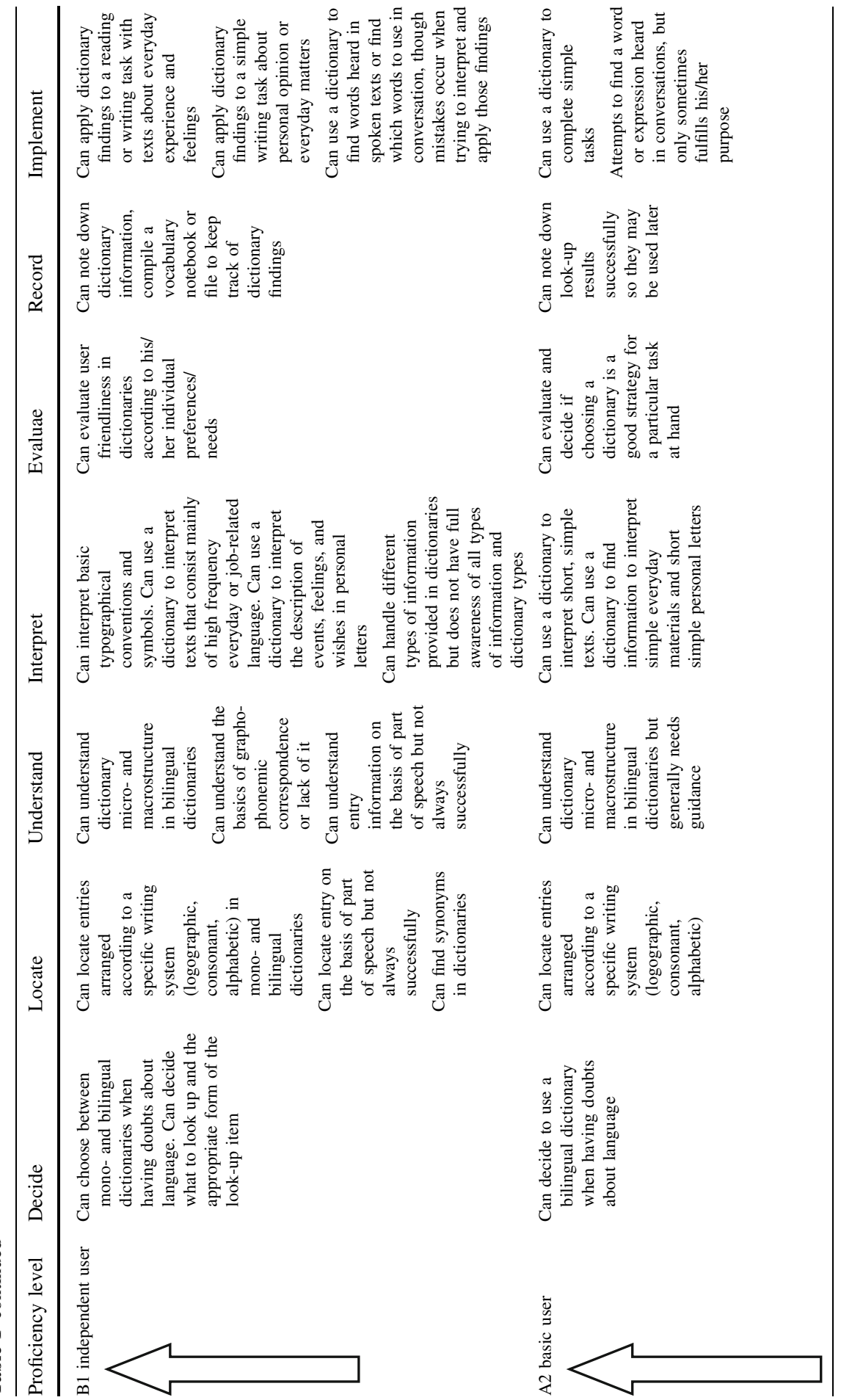

\section{Springer}




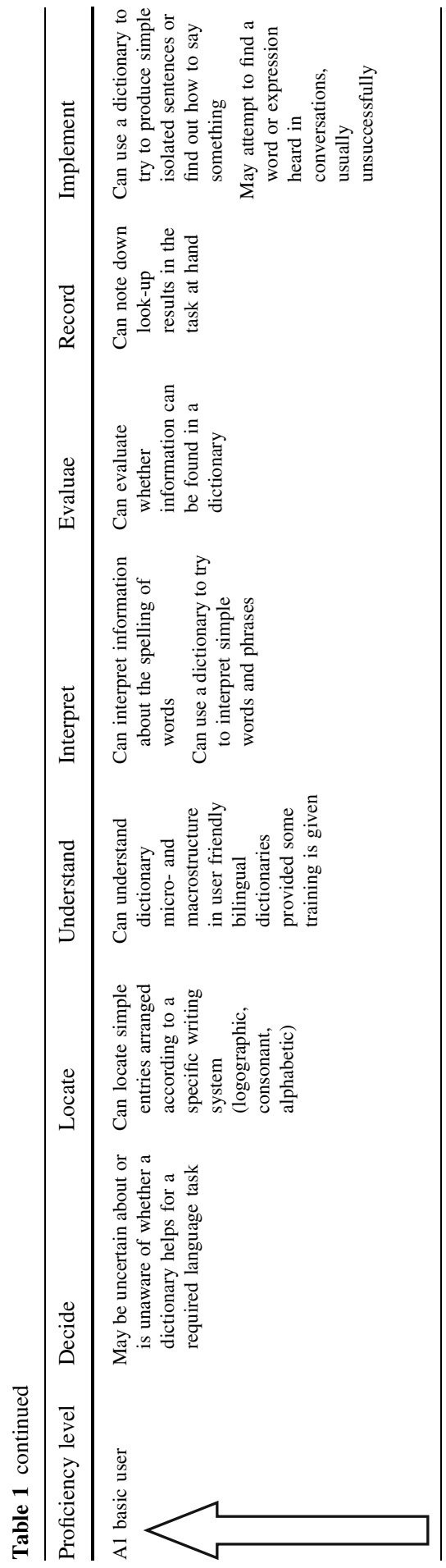


It should also be pointed out that the majority of students with access to the Internet tend to use web dictionaries that are freely available and they present further challenges as formats and contents may significantly differ from paper and even electronic dictionaries. At higher proficiency levels, consideration should be given not only to dictionaries but also to other types of complex databases, which even further complicates assessment descriptors. As far as the use of computerbased dictionaries is concerned, those dictionary users with good computer skills tend to show a higher general competence in dictionary skills, than in the other language skills. Researching the role of (computer-based) dictionary skill training to aid language learning may yield interesting results in the way students achieve proficiency in the different skills. Learners who would not use a paper dictionary but are enthusiastic about computers may show good progress if motivated by the use of computer-mediated dictionaries particularly if they are assessed in this skill and see positive results. Adult learners with good computer skills might also show the same motivation and progress if they get proper training in dictionary use.

\section{Concluding remarks}

It is important to classify dictionary skills into categories with regard to lexicographic and pedagogical resources on the Internet. For teachers, test-makers, and lexicographers to be able to make informed judgments, further research is necessary in e-dictionary use and typology.

This article has attempted to provide a review on dictionary skills and the importance of relating these skills to language proficiency levels. As new online dictionaries continue to appear, change, and evolve, new skills may be needed and be analyzed, not only for the benefit of language learners but also for other possible users in different working environments.

The dictionary skills proficiency levels described in this article can be used as a starting point to discuss other possible ways to understand dictionary skills and assign specific levels to these skills. The skills described in the rubric should be understood to be cumulative; for example, the skills in A2 are built upon those in A1.

The implementing dictionary skills stage should be further studied on its own along the lines of research of the past decades, considering to what extent the other stages have influenced the implementation stage (or have not). Besides, specific framework descriptors related to the use of dictionaries for reading, writing, speaking, and listening skills should be studied and analyzed so they may be easily related to specific tasks when assessing language skills.

\section{References}

\section{A. Electronic dictionaries}

Cambridge Dictionaries Online. http://dictionary.cambridge.org/. Collins Dictionaries. http://www.collinsdictionary.com/. 
Lexicool: Online bilingual and multilingual dictionaries. http://www.collinsdictionary.com/.

Longman Dictionary of Contemporary English Online. http://www.ldoceonline.com/.

Macmillan Dictionary. http://www.macmillandictionary.com/.

Merriam-Webster Dictionary and Thesaurus. http://www.merriam-webster.com/.

OneLook Dictionary Search. http://www.onelook.com/.

Oxford Dictionaries. http://www.oxforddictionaries.com/es/.

\section{B. Other works}

Atkins, B.T.S., and K. Varantola. 1998. Language learners using dictionaries: The final report on the EURALEX/AILA research project on dictionary Use. In Using dictionaries: Studies of dictionary use by language learners and translators, ed. B.T.S. Atkins, 83-123. Tübingen: Max Niemeyer.

Beech, John R. 2004. Using a dictionary: Its influence on children's reading, spelling and phonology. Reading Psychology 25: 19-36.

Bishop, Graham. 2000. Developing learner strategies in the use of dictionaries as a productive language learning tool. The Language Learning Journal 22(1): 58-62.

Campoy-Cubillo, Mari Carmen. 2002. General and specialised free online dictionaries. Teaching English with Technology 2(3): 42-47. http://tewtjournal.org/issues/past-issue-2002/past-issue-2002-issue-3/. Accessed 21 Dec 2014.

Campoy-Cubillo, Mari Carmen, Mercedes Querol-Julián. Work in progress. Assessing multimodal skills in English as a foreign language contexts.

Carduner, Jessie. 2003. Productive dictionary skills training: What do language learners find useful? The Language Learning Journal 28(1): 70-76.

Chi, Man Lai Amy. 1998. Teaching dictionary skills in the classroom. In Euralex' 98 proceedings. Papers submitted to the eighth EURALEX international congress on lexicography in Liège, Belgium, ed. Thierry Fontenelle, et al., 565-577. Liège: Université de Liège, Départements d'anglais et de néerlandais.

Commission of the European Communities. 2007. E-skills for the 21st Century: Fostering Competitiveness, Growth and Jobs: Communication from the Commission to the European Parliament, the Council, the European Economic and Social Committee and the Committee of the Regions. Office for Official Publications of the European Communities.

Council of Europe. 2001. Common European framework of reference for languages: Learning, teaching, assessment. Cambridge: Cambridge University Press.

Crowley, Terry. 1999. The socially responsible lexicographer in Oceania. Journal of Multilingual and Multicultural Development 20(1): 1-12.

De Schryver, Gilles Maurice. 2003. Lexicographers' dreams in the electronic-dictionary age. International Journal of Lexicography 16(2): 143-199.

East, Martin. 2008. Dictionary use in foreign language writing exams: Impact and implications, vol. 22., Language learning \& language teaching Amsterdam: John Benjamins.

Gallardo, A. 1980. Dictionaries and the standardisation process. In Theory and method of lexicography: Western and non-western perspectives, ed. L. Zgusta, 59-69. Columbia, South Carolina: Hornbeam.

Granger, Sylviane, and Magali Paquot. 2010. Customising a general EAP dictionary to meet learner needs. In eLexicography in the 21st century: New challenges, new applications, ed. Sylviane Granger, and Magali Paquot, 87-96. Louvain-la-Neuve: Cahiers du CENTAL.

Green, Anthony. 2014. Exploring language assessment and testing. Language in action.., Routledge introductions to applied linguistics London: Routledge.

Hadebe, Samukele. 2004. Improving dictionary skills in Ndebele. Lexikos 14(1): 89-104. http://www. ajol.info/index.php/lex/article/view/51412. Accessed 19 Jan 2015.

Hartmann, Reinhard R.K. 1987. Four perspectives on dictionary use: A critical review of research methods. In The dictionary and the language learner, ed. Anthony Cowie, 246-256., Papers from the EURALEX seminar at the University of Leeds, 1-3 April 1985 Tübingen: Max Niemeyer.

Hartmann, Reinhard R.K. 2000. European dictionary culture: The Exeter case study of dictionary use among university students, against the wider context of the reports and recommendations of the Thematic Network Project in the Area of Languages (1996-1999). In Proceedings of the Ninth EURALEX International Congress, EURALEX 2000: Stuttgart, Germany, August 8th-12th, 2000. 385-391. 
Hartmann, Reinhard R.K., and Gregory James. 1998. Dictionary of lexicography. London: Routledge.

Lew, Robert. 2013a. Online dictionary skills. In Electronic lexicography in the 21st century: Thinking outside the paper, ed. I. Kosem, J. Kallas, P. Gantar, S. Krek, M. Langemets, and M. Tuulik, 16-31., Proceedings of the eLex 2013 conference, 17-19 October 2013, Tallinn, Estonia Ljubljana: Trojina, Institute for Applied Slovene Studies/Eesti Keele Instituut.

Lew, Robert. 2013b. From paper to electronic dictionaries: Evolving dictionary skills. In Lexicography and dictionaries in the information age, ed. D.A. Kwary, N. Wulan, and L. Musyahda, 79-84., Selected papers from the 8th ASIALEX international conference Surabaya: Airlangga University Press.

Lew, Robert. 2014. User-generated content (UGC) in online English dictionaries. OPAL-Online publizierte Arbeiten zur Linguistik 2014(4): 8-26.

Lew, Robert. 2010. Multimodal lexicography: The representation of meaning in electronic dictionaries. Lexikos 20: 290-306. http://www.ajol.info/index.php/lex/article/view/62717. Accessed 12 Mar 2015.

Lew, Robert, and Gilles-Maurice de Schryver. 2014. Dictionary users in the digital revolution. International Journal of Lexicography 27(4): 331-359.

Lew, Robert, and Katarzina Galas. 2008. Can dictionary skills be taught? The effectiveness of lexicographic training for primary-school-level Polish learners of English. In Proceedings of the XIII EURALEX international congress, ed. Elisenda Bernal Gallén, and Janet DeCesaris Ward, 1273-1285. Barcelona: Universitat Pompeu Fabra.

Negishi, M. 2012. The development of the CEFR-J: Where we are, where we are going. In New perspectives for foreign language teaching in higher education: Exploring the possibilities of application of CEFR, ed. N. Tomimori, M. Furihata, K. Haida, N. Kurosawa, and M. Negishi, 105-116. Tokyo: WOLSEC, Tokyo University of Foreign Studies. http://www.tufs.ac.jp/common/ fs/ilr/EU_kaken/_userdata/negishi2.pdf. Accessed 14 Apr 2015.

Nesi, Hilary. 1999. The specification of dictionary reference skills in higher education. In Dictionaries in language learning. Recommendations, national reports and thematic reports from the TNP subproject 9: Dictionaries, ed. Reinhard Hartmann, 53-66. Berlin: Free University Berlin.

Pastor, Verónica, and Amparo Alcina. 2010. Search techniques in electronic dictionaries: A classification for translators. International Journal of Lexicography 23(3): 307-354.

Prinsloo, D.J. 2012. Lexicography in non-European languages. In The encyclopedia of applied linguistics, ed. Carol Chapelle, 3378-3385. Chichester, West Sussex, UK: Wiley-Blackwell.

Ranalli, J. 2013. Online strategy instruction for integrating dictionary skills and language awareness. Language Learning \& Technology 17(2): 75-99.

Ranalli, James M. 2012. The VVT project: A web-based platform for strategy instruction and research into self-regulated learning of L2 vocabulary. Graduate theses and dissertations. Paper 12953. http://lib.dr.iastate.edu/etd/12953. Accessed 7 Apr 2015.

Rundell, Michael. 1999. Dictionary use in production. International Journal of Lexicography 12(1): 35-53.

Runnels, Judith. 2014. Japanese English learners' self-assessments on the CEFR-J's A-level can-do statements using four and five-point response scales. The Asian Journal of Applied Linguistics 1(2): 167-177.

Sánchez, Maria del Mar, and Carmen Pérez Basanta. 2004. ADELEX: Using computer-mediated dictionaries to enhance vocabulary acquisition through an online educational platform-WebCT. In Computer-mediated lexicography in the foreign language learning context, vol. 18, ed. Mari Carmen Campoy-Cubillo, and Pilar Safont I. Jordà, 94-114., Col-lecció "Estudis Filològics" Castellón: Publicacions de la Universitat Jaume I.

Sánchez Ramos, Maria del Mar. 2007. El uso de los diccionarios electrónicos y otros recursos de Internet como herramientas para la formación del traductor (Inglés-Español). [The use of electronic dictionaries and other Internet resources as translator training tools (English-Spanish)]. PhD dissertation. 2004. Castelló: Universitat Jaume I. Granada: Universidad de Granada.

Schofield, P. 1999. Dictionary use in reception. International Journal of Lexicography 12(1): 13-34.

Scholfield, P. 1982. Using the English dictionary for comprehension. Tesol Quarterly 16(2): 185-194.

Tarp, Steven. 2011. Pedagogical lexicography: Towards a new and strict typology corresponding to the present state-of-the-art. Lexikos 21: 217-231.

Tono, Yukio. 1988. Assessment of the EFL learners' dictionary using skills. JACET Bulletin 19: 103-126. 
Tono, Yukio. 2000. On the effects of different types of electronic dictionary interfaces on L2 learners' reference behaviour in productive/receptive tasks. In Proceedings of the ninth Euralex international congress, EURALEX 2000, Stuttgart, Germany, August 8th-12th, 2000, ed. U. Heid, S. Evert, E. Lehmann, and C. Rohrer, 855-861. Stuttgart: Institut für Maschinelle Sprachverarbeitung, Universität Stuttgart.

Tono, Yukio. 2001. Research on dictionary use in the context of foreign language learning: Focus on reading comprehension, vol. 106., Lexicographica series Tübingen: Max Niemeyer.

Tono, Yukio. 2011. Application of eye-tracking in EFL learners' dictionary look-up process research. International Journal of Lexicography 24(1): 124-153.

Tono, Yukio, and Masashi Negishi. 2012. The CEFR-J: Adapting the CEFR for English language teaching in Japan. Framework \& Language Portfolio (FLP) SIG Newsletter 8: 5-12. http://www. tufs.ac.jp/ts/personal/tonolab/cefr-j/Tono\&Negishi2012forJALT_FLPSIG.pdf. Accessed 14 Jan 2015.

Walz, Joel. 1990. The dictionary as a secondary source in language learning. The French Review 64(1): 79-94.

White, Marilyn Domas, Miriam Matteson, and E.G. Abels. 2008. Beyond dictionaries. Journal of Documentation 64(4): 576-601.

Wingate, Ursula. 2004. Dictionary use-The need to teach strategies. Language Learning Journal 29(1): $5-11$. 